\title{
Dimensão religiosa, moral e cultural da água. Uma análise do ponto de vista do Direito Internacional.
}

\author{
Religious, moral and cultural dimension of water. An analysis from the point of view of \\ international law.
}

Gildo Manuel Espada*

Ivete Marlene Rosária Mafundza Espada**

\section{REFERÊNCIA}

ESPADA, Gildo Manuel; ESPADA, Ivete Marlene Rosária Mafundza. Dimensão religiosa, moral e cultural da água. Uma análise do ponto de vista do Direito Internacional. Revista da Faculdade de Direito da UFRGS, Porto Alegre, n. 46, p. 126-145, ago. 2021. DOI: https://doi.org/10.22456/0104-6594.107988.

\begin{abstract}
RESUMO
Quando se fala de água, é geralmente para analisá-la do ponto de vista de bem essencial para o consumo humano, strictu sensu. Isto é, como elemento essencial para a sobrevivência, considerando seus principais usos: para o abeberamento, para as lides domésticas, para a agricultura e, quiçá, para a manutenção dos ecossistemas. Quando não é esta a abordagem, a água é vista como elemento de aproximação ou separação dos povos. Isto é, como via de comunicação, ou como fonte de conflito. Em última instância, fala-se da água como parte da natureza, que tem um ciclo próprio: o ciclo da água. É este o problema que nós analisamos: será que há consciência das várias dimensões da água? Por isso, este artigo faz uma abordagem diferente da água: fala da sua dimensão cultural, moral e religiosa, com objectivo de abordar a água em perspectivas diferentes. Porque a água é um elemento essencial para a preservação dos valores morais, religiosos e culturais. O artigo foi feito com base em pesquisa bibliográfica e procura fazer uma análise global, que não se limita a nenhum país ou região. A conclusão a que chegamos é que a água tem uma importância e dimensão para a moral, religião e cultura dos povos muito maior do que é geralmente atribuída, devendo por isso incrementar a proteção e divulgação dos valores morais, culturais e religiosos deste bem que é essencial para a humanidade.
\end{abstract}

\section{PALAVRAS-CHAVE}

Direito das Águas. Religião. Cultura. Moral.

\begin{abstract}
Fresh water is generally analyzed from the point of view of an essential good for human consumption, strictu sensu. Water is referred to as an essential element for survival, with reference to its main uses: for consumption, for domestic tasks, for agriculture and, perhaps, for the maintenance of ecosystems. The tendency is to analyze water as an element of approximation or separation of people. That is, water as a means of communication or water as a source of conflict; Ultimately, there is talk of water as part of nature, which has its own cycle: the water cycle. This article intends to investigate if the many dimensions of water are a conscious concept. Thus, it provides a different approach on water: it explores its cultural, moral and religion dimensions, presenting water under different perspectives. Water is an essential element for the preservation of moral, religious and cultural
\end{abstract}

\footnotetext{
* Doutor em Direito Pela Faculdade de Direito da Universidade Nova de Lisboa. Investigador do CEDIS, da UNL. Professor Auxiliar da Faculdade de Direito da Universidade Eduardo Mondlane. Formador convidado de Magistrados Judiciais e do Ministério Público no Centro de Formação Jurídica e Judiciária de Moçambique. Advogado inscrito na Ordem dos Advogados de Moçambique.

** Doutoranda em Direito pela Faculdade de Direito da Universidade Eduardo Mondlane de Moçambique. Docente assistente universitária na mesma faculdade. Advogada e ativista de Direitos Humanos.
} 
values. The article was written based on bibliographic research, and seeks to make a global analysis, which is not limited to any country or region. It is concluded that water has a much greater importance and dimension for the morality, religion and culture of people than is generally attributed, and should therefore increase the protection and dissemination of the moral, cultural and religious values of this good that is essential for humanity.

\section{KEYWORDS}

Water Law; Religion; Culture; Moral.

\section{SUMÁRIO}

1. Introdução. 2. O uso da água: questões fundamentais. 3. A água como um bem ecológico. 4. Água como bem cultural, moral e religioso. 5. Conclusão. Referências. Dados da publicação.

\section{INTRODUÇÃO}

A água é um elemento essencial para a existência da vida na terra. Os seres vivos são compostos maioritariamente de água, sendo os seres humanos compostos por entre 60 a 80 por cento de água. Por isso, uma pessoa pode viver cerca de um mês sem alimento, mas não resistiria mais do que uma semana sem água.

Para além de ser fundamental para garantir a subsistência da vida na terra, a água é também essencial para o bem-estar social, cultural e religioso dos povos, assim como para o equilíbrio ambiental planetário. Isto acontece porque o Homem realiza as suas cerimônias religiosas na água, ou não consegue fazê-lo sem ela; O homem pratica grande parte das suas actividades de lazer na água, ou não consegue fazê-lo sem ela. Da mesma forma que culturalmente, a água está sempre presente na vida do homem não só aquando do seu nascimento, mas também ao longo da sua vida e até na sua morte: veja-se a título de exemplo os rituais de nascimento, de vida, e de morte no rio Ganges, na Índia.

As estatísticas provam que há água suficiente no mundo para responder às necessidades presentes e futuras da população mundial, satisfazer as necessidades industriais, hidroelétricas e de desenvolvimento urbano e $\operatorname{rural}^{1}$. Na verdade, a quantidade total de água existente no mundo não aumenta nem diminui, supondo-se que a quantidade de água existente hoje é a mesma que existia há três biliões de anos. Mas a questão é: Esses diversos usos são compatíveis com os usos morais, culturais e religiosos?

\footnotetext{
${ }^{1}$ BENVENISTI, Eyal. Collective Action in the Utilization of Shared Freshwater: the challenges of International Water Resources Law. The American Journal of International Law, v. 90, n. 3, p. 384-415, 1996, p. 384.
} 
Para responder a esta questão, seria, antes de mais necessários saber quais os usos morais, culturais e religiosos a que cada corpo dos diversos cursos hídricos estão sujeitos. E qual é a percentagem da população para cada um desses usos. Estes fatores fazem com que o cenário atual, no que ao acesso à água diz respeito, se mostre preocupante e até drástico, comparativamente com a situação que existia nos primórdios da humanidade, em que o Homem guiava-se mais pelos seus instintos.

Todavia, para que tal análise seja feita, é preciso fazer alusão a um facto pouco referido mas incontornável: o facto de a água ter uma dimensão moral, religiosa e cultural, que é, algumas vezes, tão relevante quanto os demais usos, mais comuns, da água. É esta a razão principal que nos levou a enveredar pelo presente estudo, com vista a fazer ressaltar e realçar as dimensões menos estudadas da água com bem de utilidade pública, o que fazemos recorrendo, essencialmente, à pesquisa bibliográfica em obras especializadas.

Naturalmente, e guiados pela lógica do raciocínio jurídico inerente ao Direito, torna-se inevitável inferir as várias implicações e ou consequências decorrentes da existência e inexistência da água e a alocação para os diversos fins, tal como torna-se necessário descortinar soluções para as muitas questões legais que o elemento água suscita em todas as sociedades modernas. E isto passa por uma premissa: a análise da água como bem social, religioso e cultural.

\section{O USO DA ÁGUA: QUESTÕES FUNDAMENTAIS}

São vários os fins a que se destinam as águas do planeta. As mesmas podem servir de fronteira entre os Estados. A água tem também um importante papel económico, como bem de alto valor económico, para produção de energia, para a agricultura, a indústria e, acima de tudo, considerando que é o mais importante elemento natural de que o homem se socorre para manter a sua vida, para satisfazer as suas necessidades humanas básicas, seja para fins de lazer ou outros que se podem apontar.

É neste desiderato que surge a necessidade de, antes mesmos de pensarmos nas grandes discussões despoletadas pelos cursos de água, sejam nacionais ou internacionais, esclarecermos como é que, do ponto de vista de iure, a água deve ser vista do ponto de vista sócio ambiental, cultural e religioso. Há muito interesse em provar a mais-valia da existência e acesso à água para fins culturais, sociais e religiosos, mas pouco ainda se discute, do ponto de vista legal, o 
elemento água como bem jurídico sujeito a tal tutela e qual a dimensão da necessidade de regulação.

Estimativas apontam para uma crise mundial de água que no ano 2025 afetará dois terços da população mundial, que não terá água potável suficiente para satisfazer as suas necessidades ${ }^{2}$ ${ }^{3}$, na medida em que a poluição, as mudanças climáticas, o uso insustentável e um crescimento exacerbado da população mundial têm comprometido a segurança dos recursos de água existentes. $^{4}$

Espera-se ainda que até ao ano 2215 mais de três biliões de pessoas vivam em países com stress hídrico ${ }^{5}$ e a escassez da água aumentará tensões no Oriente Médio, na África subsaariana e no Norte da China. ${ }^{6}$

A escassez de água e a inacessibilidade de recursos aqui analisados não são mero espectro do futuro. ${ }^{7}$ Presentemente, as estimativas mostram que 1.1 bilião de pessoas não têm acesso à água potável, 2.4 biliões de pessoas não tem acesso a serviços sanitários e a limitação de água afeta atualmente a mais de 450 milhões de pessoas em 29 países. ${ }^{8}$ Atualmente, a água é considerada escassa em 14 por cento dos países a nível mundial, e somente 35 por cento dos países têm disponíveis mais de 10.000 metros cúbicos per capita disponíveis ${ }^{9}$.

\footnotetext{
2 Vide NARDONE, Rona. Like Oil and Water: the WTO and the World's Water Resources. Connecticut Journal of International Law, v. 19, n. 1, p. 183-208, 2003, p.183.

3 Prevê-se que países como o Paquistão, África do Sul, Índia e China passem por crises de escassez absoluta de água. Vide MARAVILLA, Christopher Scott. The Canadian Bulk Water Moratorium and Its Implications for NAFTA. Currents: International Trade Law Journal, v. 10, n. 1, p. 29-36, 2001, p. 29.

${ }^{4}$ Vide WORLD WATER FORUM. Ministerial Declaration of the Hague on Water Security in the $21^{\text {st }}$ Centuary. Second World Water Forum, 2000. Disponível em: 〈http://www.worldwaterforum.net/index2.html〉. Acesso em 12 Mar. 2013. Vide igualmente WOUTERS, Patricia; SALMAN, Salman M. A.; JONES, Patricia. The Legal Response to the World's Water Crisis: What Legacy from the Hague - What Future in Kyoto. University of Denver Water Law Review, v. 4, n. 2, p. 418-425, 2001.p. 420.

${ }^{5}$ Um país que esteja sob stress hídrico é aquele no qual a precipitação anual é menor que 1,700 metros cúbicos per capita por ano. Vide MARAVILLA, Christopher Scott. The Canadian Bulk Water Moratorium and Its Implications for NAFTA. Currents: International Trade Law Journal, v. 10, n. 1, p. 29-36, 2001.p. 30.

${ }^{6}$ Vide MARAVILLA, Christopher Scott. The Canadian Bulk Water Moratorium and Its Implications for NAFTA. Currents: International Trade Law Journal, v. 10, n. 1, p. 29-36, 2001. p. 30.

${ }^{7}$ Hidrologistas sugerem que uma região pode ser considerada como sofrendo de escassez de água aguda quando os níveis de água renovável se encontrem abaixo dos 1,000 metros cúbicos por ano per capita. Vide NICHOLSON, Simon. Water Scarcity. Conflict and International Water Law: an Examination of the Regime Established by the UN Convention on International Watercourses. New Zealand Journal of Environmental Law, v. 5, p. 91-126, 2001, p. 94.

${ }^{8}$ Vide WOUTERS, Patricia; SALMAN, Salman M. A.; JONES, Patricia. The Legal Response to the World's Water Crisis: What Legacy from the Hague - What Future in Kyoto. University of Denver Water Law Review, v. 4, n. 2, p. 418-425, 2001, p. 419. Note-se, todavia, que as limitações da água não afectam somente o consumo doméstico e industrial. Estes mesmos países não terão água suficiente para a irrigação e abeberamento do gado, por exemplo. MARAVILLA, Christopher Scott. The Canadian Bulk Water Moratorium and Its Implications for NAFTA. Currents: International Trade Law Journal, v. 10, n. 1, p. 29-36, 2001.p. 30.

9 Vide WEISS, Edith Brown. The Evolution of International Water Law. Leiden/Boston: Martinus Nijhoff Publishers, 2009., p. 178. Refira-se ainda que a linha de pobreza para o acesso à água potável é de 1000 metros cúbicos por pessoa por ano, e que três quartos da população mundial encontra-se em situação de acesso limitado
} 
De acordo com certos autores, existem três tipos de escassez de água: escassez estrutural, escassez induzida pela procura e a escassez induzida pela oferta. ${ }^{10} \mathrm{~A}$ "escassez estrutural" refere-se ao facto de a água estar distribuída de forma desigual, facto que muitas vezes passa despercebido ou é erradamente interpretado porque no geral ficamos com a ideia de o nosso planeta ser abundante em água pelas imagens do mesmo, vistas do espaço, que indicam uma aparente abundância de água, não se relacionando, por exemplo, a abundância da água com os mares e oceanos.

A "escassez induzida pela procura" surge em resultado do aumento da procura da água, exacerbada pela crescente exploração da água devido ao crescimento da população e pelas pressões do desenvolvimento, tendo este tipo de escassez um maior impacto em regiões áridas e semiáridas, nas quais já se verificavam problemas de escassez de água. ${ }^{11}$

A "escassez induzida pela oferta" refere-se à degradação dos recursos hídricos num ritmo mais rápido do que o necessário para a reposição natural do recurso. A poluição e o uso insustentável de águas subterrâneas são dois dos fatores que mais contribuem para este tipo de escassez. ${ }^{12}$

Dos três tipos de escassez referidos, não há dúvidas que a escassez estrutural é a mais preocupante de todas porque, na verdade, um dos maiores problemas relacionados com a água é a sua localização geográfica ${ }^{13}$ e a história de subdesenvolvimento de alguns países que

\footnotetext{
à água, havendo estimativas que indicam que até 202535 por cento da população mundial, que reside em 52 países, estará em situação de stress hídrico ou mesmo de escassez de água.

${ }^{10}$ Vide PERCIVAL, Val.; HOMER-DIXON, Thomas. Environmental Scarcity and Violent Conflict: the case of South Africa, Journal of Peace research, v. 35, n. 3, p. 279-298, 1998., p.280.

${ }^{11}$ Vide NICHOLSON, Simon. Water Scarcity. Conflict and International Water Law: an Examination of the Regime Established by the UN Convention on International Watercourses. New Zealand Journal of Environmental Law, v. 5, p. 91-126, 2001, p. 95. Para estatísticas em relação à disponibilidade de água e respectivo uso, por país, vide WORLD BANK. World Development Indicators. 2005. Disponível em <http $\mid$ www.worldbank.org/data/wdi/environment.html>. Acesso em: 13 Fev. 2017.

${ }^{12}$ Vide NICHOLSON, Simon. Water Scarcity. Conflict and International Water Law: an Examination of the Regime Established by the UN Convention on International Watercourses. New Zealand Journal of Environmental Law, v. 5, p. 91-126, 2001, p. 97. Um outro problema é o que está relacionado com as perdas durante o transporte urbano. A necessidade de transportar a água de locais distantes para os locais de consumo leva a perdas massivas devido à evaporação e a fugas de água (estas últimas responsáveis pela perda de entre 30 a $50 \%$ da quantidade total da água transportada).

${ }^{13}$ De facto, tal como o Professor MCCAFFREY, Stephen, afirma, "if you took the total available water and divided it by the number of people on the planet, there would be plenty of water to go around. The problem is it's in the wrong places!" Vide MCCAFFREY, Stephen C. Water, Water Everywhere, but too Few Drops to Drink: the Coming Fresh Water Crisis and International Environmental Law. Denver Journal of International Law \& Policy, v. 28, n. 3, p. 325-338, 2000, p. 330. Vide igualmente LUTERBACHER, Urs; WIEGANDT, Ellen. Cooperation or Confrontation: Sustainable Water Use in an International Context. In: WEISS, Edith Brown; CHAZOURNES, Laurence Boisson de; BERNASCONI-OSTERWALDER Nathalie. Fresh Water and International Economic Law. Oxford; New York: Oxford University Press, 2005, p. 12, que referem que uma parte do problema da distribuição da água está relacionado com a divisão do globo em regiões húmidas, semiáridas e áridas.
} 
partilham cursos de água internacionais, quando comparados com outros países que partilham a mesma bacia hidrográfica.

A questão que se coloca liga-se à necessidade que os países têm de fazer a exploração dos recursos hídricos, para o que devem desenvolver sistemas de distribuição e gestão da água, e para tal precisam quase sempre reabilitar ou construir as infraestruturas necessárias para um melhor uso e gestão das águas em benefício das populações.

Mas isto tem que ser feito, muitas vezes, num contexto de possíveis reclamações provenientes dos demais Estados de bacia, tratando-se de rios internacionais, porque os demais países também têm interesses a proteger, situação esta que se torna mais complicada nos casos em que determinados países alcançaram níveis muito altos de desenvolvimento que demandam altos níveis de uso de água, enquanto outros não puderam desenvolver por razões económicas ou políticas.

O problema, neste caso, tem também a ver com a distribuição desigual da água, que, tal como afirma o Professor Canelas de Castro, aparece em unidades naturais dividida entre os Estados, atravessando fronteiras ou formando-as, ${ }^{14} \mathrm{e}$ dessa forma justificando a sua natureza fugitiva. ${ }^{15}$

Os números mostram que há mais de 250 rios no planeta que são internacionais (atravessam dois ou mais Estados ou formam fronteira entre dois ou mais Estados), e as bacias hidrográficas partilhadas ocupam cerca de 50 por cento da superfície terrestre, e porque de facto a procura mundial de água cresce diariamente a nível internacional, assiste-se, hoje em dia, a uma verdadeira crise internacional. ${ }^{16}$

\footnotetext{
14 Vide CANELAS DE CASTRO, Paulo. The Future of International Water Law. Lisboa: Luso-American Foundation, 2005, p. 12, que explica, de forma incisiva, que "a lógica omnipotente ('suprema potestas') da afirmação da 'propriedade' soberana ('dominium'), que é expressa na máxima Romana 'ius utendi, fruendi et abutendi', e que é ainda aplicada nos dias de hoje para a terra, nunca foi aplicável à água, porque a água é geralmente encontrada em cursos correntes, que tal como o próprio nome sugere (curso de água) é móvel, não respeitando soberanias ou jurisdições demarcadas por fronteiras e sinalizadas por administrações". (Ênfase original).

${ }^{15}$ A expressão "propriedade fugitiva” pertence a COOTER, R.; ULEN, T. Law and Economics (2 ${ }^{\text {nd }}$ edition, 1997), citados por NICHOLSON, Simon. Water Scarcity. Conflict and International Water Law: an Examination of the Regime Established by the UN Convention on International Watercourses. New Zealand Journal of Environmental Law, v. 5, p. 91-126, 2001, p. 93.

16 Vide CANELAS DE CASTRO, Paulo. The Future of International Water Law. Lisboa: Luso-American Foundation, 2005, p. 12. E não é difícil de perceber tal situação: porque a água não é um recurso fisicamente estático, a competição pela água envolve diferentes conjuntos de conflitos; Por um lado porque os rios são usados por milhares de pessoas, e esta situação é geradora de conflitos, e por outro lado, porque o próprio ciclo da água, com as suas épocas altas e baixas, acaba causando outros conflitos entre os utentes. Vide DU BOIS, François. Water Rights and the Limits of Environmental Law. Journal of Environmental. Law, v. 6, n. 1, p. 73-84, 1994, p. 77.
} 
Para além disso, os oceanos contêm 97 por cento de toda a quantidade de água do planeta (e enquanto o processo de dessalinização da água do mar continuar muito oneroso, o mundo não pode usufruir da abundância da água do mar pois a mesma é imprópria para beber, para a agricultura ou para fins industriais). ${ }^{17}$

Deste modo, considerando que só três por cento da quantidade total de água existente no planeta é doce, correspondente a um volume total de aproximadamente 35 milhões de quilómetros cúbicos, e ainda assim, grande parte desta água potencialmente útil estar para além do alcance imediato do homem, pois uma parte encontra-se nas calotes polares, em glaciares ou ainda em profundos aquíferos subterrâneos, somente 0.3 por cento das reservas totais de água (menos de 100,000 km3) estão disponíveis em rios e lagos, nos quais grande parte da população mundial depende, para satisfazer as suas necessidades. ${ }^{18}$

E como se depreende, vezes sem conta estes factos causam desentendimentos e até disputas, que são vistos como problemas clássicos e modernos do Direito de Águas, ${ }^{19}$ uma vez que a disponibilidade de água em quantidade suficiente é importante não só para salvaguardar o desenvolvimento económico e a robustez ecológica, mas também para salvaguardar a paz e segurança internacionais. ${ }^{20}$

Se é um facto a problemática da quantidade reduzida de água, não é menos preocupante a questão da qualidade de água, que é posta em causa devido a problemas ligados à poluição. A poluição reduz a quantidade de água disponível, uma vez que pode torna-la inútil, por culpa

\footnotetext{
${ }^{17}$ É possível, por técnicas de dessalinização, que incluem a destilação e osmose reversa, converter água salgada ou água salobra em água potável. Todavia, estes processos requerem o uso de tecnologia de ponta, bastante onerosa, o que torna o processo todo bastante oneroso, e logo, pouco acessível. O World Research Institute estima que a dessalinização custa três a quarto vezes mais que as técnicas usuais de retirada da água dos cursos de água ou aquíferos subterrâneos. Vide NICHOLSON, Simon. Water Scarcity. Conflict and International Water Law: an Examination of the Regime Established by the UN Convention on International Watercourses. New Zealand Journal of Environmental Law, v. 5, p. 91-126, 2001., p. 93.

${ }^{18}$ Os dados diferem, de acordo com as fontes, embora a magnitude seja próxima, nas diversas apreciações. Os dados aqui apresentados foram retirados de GLEICK, Peter H. An introduction to Global Fresh water Issues. In: GLEICK, Peter H. (ed). Water in Crisis: a Guide to the World's Fresh Water Resources. New York: Oxford University Press, 1993, p. 198.

${ }^{19}$ Com a mesma opinião, mas numa análise do caso do Afeganistão, vide TARLOCK A. Dan; MCMURRAY, James C. The Law of Later Developing Riparian States: the case of Afghanistan. New York University Environmental Law Journal., v. 12, n. 3, p. 711-763, 2004, p. 745.

${ }^{20}$ Vide, todavia, o paradoxo apresentado pelo caso entre o Canadá e os Estados Unidos, em relação à bacia dos Grandes Lagos: comparada à maioria das mais contestadas bacias hidrográficas, tais como a Amu Darya na Ásia Central, à Bacia do Rio Nilo, ou ainda do rio Zambeze, o nível de controvérsia em relação ao uso e gestão das águas dos Grandes Lagos é inverso em relação à quantidade de água disponível naquela bacia. Isto é, os lagos contêm $20 \%$ da quantidade total de água superficial existente no planeta. Todavia, em termos comparados, muito pouca água é usada nesta bacia, em quantidades que não ultrapassam os cinco por cento. Para mais discussões em relação à situação dos Grandes Lagos, vide TARLOCK, A. Dan. Five Views of the Great Lakes and Why They Might Matter. Minnesota Journal of International Law, v. 15, n. 1, p. 21-41, 2006.
} 
das actividades agrícola e industrial, principalmente, o que faz que algumas vezes as pessoas consumam água inadequada, que acaba sendo um vetor de doenças.

Outras razões como a mudança do uso que se faz da água, como forma de acompanhar o desenvolvimento económico, é outro fator que pode exacerbar potenciais conflitos. ${ }^{21}$ Isto acontece, por exemplo, no caso do Afeganistão, que é visto como um verdadeiro pesadelo do clássico regime de cursos de água transfronteiriços ${ }^{22}$, pois é um país cujo desenvolvimento deuse tardiamente e agora exige dos países com quem partilha rios internacionais o direito de acesso a uma quantidade de água que lhe permita alcançar os seus planos sociais e económicos, o que se torna agora bastante difícil de materializar, em face da intensa exploração que é feita pelos demais Estados ribeirinhos, que não só construíram infraestruturas de gestão, retenção e distribuição de águas, como também tem usado a água para diversos fins cujas metas foram traçadas a longo prazo. ${ }^{23}$

Outro excelente exemplo das crises que podem ser originadas pela água pode ser encontrado na China, que é o país mais populoso do mundo, e igualmente um dos países mais carentes de água do mundo, devido às limitações que enfrenta. ${ }^{24} \mathrm{~A}$ 'disponibilidade desproporcional de água', tanto no tempo assim como no espaço, agrava a situação da água na China, já bastante crítica. De facto, os recursos hídricos da China estão geograficamente desigualmente distribuídos; existe muito mais água no sul do que no norte. $\mathrm{O}$ sul da China, incluindo a região de Changjiang, alberga 53.5 por cento da população chinesa, em uma área

\footnotetext{
${ }^{21}$ Vide LUTERBACHER, Urs; WIEGANDT, Ellen. Cooperation or Confrontation: Sustainable Water Use in an International Context. In: WEISS, Edith Brown; CHAZOURNES, Laurence Boisson de; BERNASCONIOSTERWALDER Nathalie. Fresh Water and International Economic Law. Oxford; New York: Oxford University Press, 2005. [s. p.], que afirmam que essa competição existe não só em regiões geográficas mas também entre tipos de usuários. A agricultura, a indústria, a produção de energia e os usos domésticos exigem todos cada vez maiores fornecimentos de água, sendo certo que as quantidades do recurso regra geral não aumenta, por razões como as mudanças climáticas, sobre-uso ou ainda devido à poluição.

${ }^{22}$ Esta expressão pertence a TARLOCK A. Dan; MCMURRAY, James C. The Law of Later Developing Riparian States: the case of Afghanistan. New York University Environmental Law Journal., v. 12, n. 3, p. 711-763, 2004. p. 713.

${ }^{23}$ Outro exemplo clássico é o da Etiópia, que contribui com $85 \%$ do fluxo do Rio Nilo, à jusante para o Sudão e o Egipto. Mas o Egipto invoca usos históricos para controlar o rio Nilo e bloquear quaisquer empreendimentos de vulto que requeiram o uso da água. Vide DELLAPENNA, Joseph W. The Two Rivers and the Land Between: Mesopotamia and the International Law of Transboundary Waters. Brigham Young University (BYU) Law Review, v. 10, n. 2 , p. 213-261, 1996. p. 220.

${ }^{24}$ Vide WOUTERS, Patricia; HU, Desheng; ZHANG, Jiebin; TARLOCK A. Dan; ANDREWS-SPEED, Philip. The New Development of Water Law in China. University of Denver Water Law Review, v. 7, n. 2, 243-308, 2004. p. 250.
} 
correspondente a 36.5 por cento da área total do território chines. Entretanto, nesta mesma região, encontra-se 80.9 por cento da quantidade total dos recursos hídricos do país. ${ }^{25}$

Em contrapartida, o norte da China, incluindo as regiões de Liaohe, Hailuanhe, Huanghe, Huaihe, alberga 46.5 por cento da população total do país, em uma área que corresponde a 63.5 por cento do território nacional, para os quais estão meramente disponíveis 19.1 por cento da quantidade total de água do país. ${ }^{26}$

Consequentemente, a distribuição desigual de água é apontada como uma das causas primárias da falta de desenvolvimento social e económico deste país, no qual mais de 400 das suas 668 grandes cidades sofre de limitações de água, incluindo Beijing (com uma população de 15.36 milhões em 2012), Tianjin (11.19 milhões) Xi'an (9.03), Taiyuan (5.22 milhões), Datong (5.05 milhões), Qingdao (9.16 milhões), Yantai (8.45 milhões) e Dalian (7.58 milhões). ${ }^{27}$

Em face do exposto, e na procura de soluções para estes problemas, e porque as quantidades de água são fixas, discute-se como aumentar as quantidades de água disponíveis. Obviamente que a resposta deve ser a necessidade de recurso a melhores práticas e hábitos, que devem ser buscados na disciplina do Direito do Ambiente, recorrendo à reciclagem das águas, à captação das águas da chuva, e outros métodos e técnicas ambientalmente recomendáveis, por um lado, e por outro, o uso de tecnologias para a conservação da água que muitas vezes abunda em certos períodos e escasseia noutros, construindo diques e canais.

Em Agosto de 2002, os delegados à Cimeira das Nações Unidas sobre Desenvolvimento Sustentável, decorrida em Joanesburgo, comprometeram-se em reduzir o número de pessoas sem acesso à água potável em 50 por cento, até ao ano 2015, mas sublinharam que para tal seria necessária cooperação entre os países. ${ }^{28}$ Por outras palavras, isto significa que a comunidade internacional terá que trabalhar em conjunto para ultrapassar os desafios culturais, financeiros, legais e operacionais para que juntos ultrapassem a crise de água mundial, pois este não é um

\footnotetext{
${ }^{25}$ WOUTERS, Patricia; HU, Desheng; ZHANG, Jiebin; TARLOCK A. Dan; ANDREWS-SPEED, Philip. The New Development of Water Law in China. University of Denver Water Law Review, v. 7, n. 2, 243-308, 2004. p. 250.

${ }^{26}$ WOUTERS, Patricia; HU, Desheng; ZHANG, Jiebin; TARLOCK A. Dan; ANDREWS-SPEED, Philip. The New Development of Water Law in China. University of Denver Water Law Review, v. 7, n. 2, 243-308, 2004. p. 250.

${ }^{27}$ WOUTERS, Patricia; HU, Desheng; ZHANG, Jiebin; TARLOCK A. Dan; ANDREWS-SPEED, Philip. The New Development of Water Law in China. University of Denver Water Law Review, v. 7, n. 2, 243-308, 2004. p. 252.

${ }^{28}$ WOUTERS, Patricia; HU, Desheng; ZHANG, Jiebin; TARLOCK A. Dan; ANDREWS-SPEED, Philip. The New Development of Water Law in China. University of Denver Water Law Review, v. 7, n. 2, 243-308, 2004. p. 183.
} 
problema de uma só nação ou povo, mas de toda a Humanidade. Porque enquanto não houver consenso sobre como mitigar a crise de água, haverá sempre o receio de os conflitos e disputas latentes poderem transformar-se em verdadeiras guerras.

Daí que questões relativas ao quadro normativo interno vigente nos vários Estados podem ser mais ou menos favoráveis à redução dos défices de acesso à água, e dos problemas que daí podem advir. Porque há uma relação direta entre a escassez de água e a falta de acesso à mesma e o direito vigente, na medida em que a existência ou não de um quadro jurídico favorável ao acesso à água pelas populações pode determinar o maior ou menor grau de carência do recurso por essas mesmas populações, uma vez que, por exemplo, havendo um ónus legal por parte do Estado em providenciar o acesso mínimo de água o mesmo tem que fazer os esforços mínimos necessários para garantir que tal direito seja de facto efetivado, sob pena de colocar-se em situação de incumprimento e sujeitar-se a todos os tipos de pressão.

Entretanto, é um facto que a escassez de água, não sendo um facto novo, teve sempre os mais diversos tipos de soluções ao longo da história comum da civilização humana. Na verdade, o nível de desenvolvimento das sociedades esteve sempre dependente da quantidade e qualidade de água disponível, pois esta sempre condicionou questões como alimentos, energia, transporte e indústria, nos vários momentos da civilização humana.

E, sempre que houve crises ou escassez de água, foi possível encontrar métodos e meios de ultrapassar as crises existentes. Pelo que a procura contínua de soluções para os problemas da água mais não é que um diapasão da própria evolução humana, com a diferença de se estar em outros tempos, com outro tipo de meios, e recurso a outras técnicas que podem ser mais ou menos onerosas, e por isso deve-se afirmar, desde já, que a atual crise de água não será ultrapassada simplesmente com base nas novas tecnologias, como a dessalinização, por exemplo, mas com base em soluções transversais que levam em conta uma matriz social e ideológica dos povos. ${ }^{29}$ Como se depreende, as limitações do acesso à água acabam se tornando verdadeiros motores de inovação da Humanidade, motivando, encorajando e incentivando as populações a descobrir novas formas de solucionar os problemas de escassez de água.

\footnotetext{
${ }^{29}$ HASSAN, Fekri A. Water Management and Early Civilizations: from Cooperation to Conflict. In: UNESCO. History and Future of Shared Water Resources. [s. l.]: UNESCO-IHP, 2003. (PC/CP series, n. 6). [p. 110-127]. p. 115.
} 


\section{A ÁGUA COMO UM BEM ECOLÓGICO}

A questão da água (doce) tem sido apontada como um dos maiores desafios que o mundo enfrenta atualmente ${ }^{30}$. De facto, a importância vital da água como recurso necessário para a subsistência humana, e como elemento necessário para o desenvolvimento socioeconómico das sociedades, é tal que justifica-se, na maior plenitude, o ditado 'sem água não há vida'31.

Entretanto, se considerarmos a quantidade de água existente no mundo e o número de habitantes existentes no planeta, haveria água suficiente para todos ${ }^{32}$. Todavia, o desafio que se coloca em relação à água é o facto de ela estar mal distribuída ${ }^{33}$. Esta distribuição desigual da água é elucidada com factos concretos, que mostram que as regiões áridas (que são os locais nos quais a evaporação é maior que a precipitação) compõem 33\% da Europa, 60\% da Ásia, $85 \%$ da África, quase toda a Austrália e parte significativa da América do Norte ${ }^{34}$.

A água é um bem ecológico. Simplesmente, porque é o elemento básico do ecossistema aquático. De igual modo, o ciclo hidrológico é um processo que por natureza e por definição, não ocorre sem a existência de água. De igual modo, o Homem, os animais e as plantas não sobrevivem sem a água.

Os benefícios ecológicos, os custos e os usos da água são, por isso, difíceis de estimar. Primeiro, porque a água é ao mesmo tempo um recurso renovável e não renovável ${ }^{35}$. Segundo,

\footnotetext{
${ }^{30}$ WEISS, Edith Brown. The Evolution of International Water Law. Leiden/Boston: Martinus Nijhoff Publishers, 2009, p. 177.

${ }^{31}$ Referindo estudos que apontam a água como uma das preocupações principais da humanidade no futuro próximo, vide SERRA, Carlos Manuel; CUNHA, Fernando. Manual de Direito do Ambiente. 2 ed. Maputo: Centro de Formação Jurídica e Judiciária, 2008, p. 51.

${ }^{32}$ A água cobre $2 / 3$ da superfície terrestre, sendo todavia somente $3 \%$ desta água doce, porque $97 \%$ de toda a água existente está nos oceanos, sendo portanto salgada. Considerando a percentagem de água doce existente, importa referir que dessa porção $77 \%$ está retida nos glaciares e icebergs, não sendo directamente aproveitável e $22 \%$ constituem água subterrânea (aquíferos), que, por vezes, se localizam a grandes profundidades, o que impede ou dificulta a sua captação. Assim, apenas uma reduzida percentagem de água (1\%) se encontra nos rios, lagos e solo, podendo ser directamente aproveitada pelo homem. Se excluirmos as reservas de gelo das calotes polares e glaciares, a água doce utilizável representa apenas $0.6 \%$ da água do nosso planeta, que se reparte desigualmente pelas diversas regiões continentais. Destes $0,6 \%$ de água doce utilizável, $97 \%$ correspondem a águas subterrâneas (aquíferos), representando os rios e os lagos uma percentagem muito pequena.

${ }^{33}$ Se toda a água doce existente no planeta fosse dividida equitativamente pela população mundial, haveria entre 5.000 e $6.000 \mathrm{~m} 3$ para cada indivíduo por ano. Tendo em conta que um indivíduo necessita no mínimo, por ano, de $1700 \mathrm{~m} 3$ este cálculo mostra que existe de facto água em abundância para todos. Disponível em: <http://www.fao.org/3/i7959e/i7959e.pdf> . Acesso em: 18 jun. 2021.

34 Vide WEISS, Edith Brown. The Evolution of International Water Law. Leiden/Boston: Martinus Nijhoff Publishers, 2009, p. 178.

${ }^{35}$ Em grande parte das suas formas, a água é um recurso renovável, que se torna disponível por via do ciclo hidrológico. Todavia, nem todas as águas naturais são renováveis. Por outro lado, águas naturais renováveis podem transformar-se em não renováveis em consequência da actividade humana.
} 
e mais importante ainda é que alguns recursos de água, que são renováveis, são igualmente esgotáveis. E a explicação é simples: o processo de renovação natural da água pode ser extremamente moroso, e a extração em larga escala dos recursos hídricos pode superar os níveis de reposição e transformar o que inicialmente era um recurso de água renovável em um recurso não renovável.

De acordo com a FAO, mais de 2.8 biliões de pessoas em 48 países estarão em situação de stress hídrico ou de escassez de água, até 2025, e até 2050 esse número de países pode subir para $54^{36}$. O conceito de stress hídrico, baseia-se no confronto entre as necessidades mínimas de água per capita para manter uma qualidade de vida adequada em regiões moderadamente desenvolvidas situadas em zonas áridas. A definição baseia-se no pressuposto de que 100 litros diários (36,5 m³/ano) representam o requisito mínimo para suprir as necessidades domésticas e a manutenção de um nível adequado de saúde 37 .

Outros fatores como as mudanças climáticas, a poluição, a destruição de lençóis de água, e o desflorestamento, também afetam negativamente a renovação dos recursos hídricos, alterando a qualidade, o tempo de renovação e o fluxo de águas subterrâneas ${ }^{38}$. Finalmente, uma avaliação ecológica correta da água é dificultada pelo impacto do stress ambiental sobre a água que é muitas vezes cumulativo, remoto no tempo, subestimado e imprevisível ${ }^{39}$. Em poucas palavras, a humanidade deve mudar de comportamento, porque não se pode simplesmente distorcer o balanço hidrológico das reservas de água existentes e esperar-se que não haja efeitos perniciosos. Pelo contrário: trata-se aqui de uma questão de sobrevivência!

Quase sempre, o volume total de água de cada país não é de grande importância, pois está diretamente relacionado com a sua área geográfica. Esta afirmação torna-se mais verdadeira se considerarmos que muitos dos rios e lagos existentes no planeta são partilhados por dois ou mais países, o que conjugado com muitos outros fatores como a qualidade, o acesso,

\footnotetext{
${ }^{36}$ FOOD AND AGRICULTURE ORGANIZATION OF THE UNITED NATIONS. Water for Sustainable Food and Agriculture: a report produced for the G20 Presidency of Germany. Rome: FAO, 2017. Disponível em: <http://www.fao.org/3/i7959e/i7959e.pdf >.Acesso em: 18 jun. 2021.

37 Vide FOOD AND AGRICULTURE ORGANIZATION OF THE UNITED NATIONS. Coping with water scarcity: an action framework for agriculture and food security. Rome: FAO, 2012. Disponível em: <https://www.un.org/waterforlifedecade/scarcity.shtml>. Acesso em: 8 jun. 2021.

38 Vide TARLOCK, A. Dan. How well can International Water Allocation Regimes Adapt to Global Climate Change? Denver Journal of International Law \& Policy, v. 9, p. 423-450, 2000. Vide igualmente GLEICK, Peter et al. The Risks and Benefits of Globalization and Privatization of Fresh Water. Oakland: Pacific Institute For Studies in Development, Environment and Security, 2002, p. 5.

${ }^{39}$ Vide TARLOCK, A. Dan. How well can International Water Allocation Regimes Adapt to Global Climate Change? Denver Journal of International Law \& Policy, v. 9, p. 423-450, 2000, p. 427 (referindo a grande incerteza sobre as questões das mudanças climáticas relacionadas com a água).
} 
o uso e a distribuição desses recursos, pode levar-nos à conclusão de que a variabilidade entre os valores máximos e mínimos de recursos hídricos disponíveis, mesmo sendo muito alta, pode contribuir para a geração de problemas sazonais de escassez, e eventualmente de conflitos, entre os vários utentes.

A água disponível per capita reduziu-se em termos globais em cerca de 80 por cento, no século passado, e sendo este um processo contínuo, há cada vez maior escassez de água, maiores disputas, uma redução da "fluidez ambiental" e provavelmente maior uso insustentável da água ${ }^{40}$, sendo por isso a garantia da água para satisfação das necessidades básicas humanas, dos ecossistemas, da agricultura, indústria, recreação, etc., um verdadeiro desafio.

A referência ao facto de a existência de água para a satisfação de necessidades humanas ser um verdadeiro desafio nos dias de hoje não significa que outras ações antrópicas não possam ser realizadas com vista a minimizar o problema. Tendo em conta a demanda dos recursos hídricos a nível mundial, e as ações antrópicas para satisfazer tal demanda de água - construção de poços, barragens, açudes, aquedutos, sistemas de abastecimento, sistemas de drenagem, projetos de irrigação e outras estruturas - constata-se, mesmo assim, que aproximadamente $20 \%$ dos 5,7 bilhões de habitantes da Terra sofre com a falta de um sistema de abastecimento confiável de água e, além disso, mais de $50 \%$ da população não dispunha de um sistema adequado de instalações sanitárias ${ }^{41}$.

\section{4 ÁGUA COMO BEM CULTURAL, MORAL E RELIGIOSO}

A água é um bem que tem uma dimensão cultural, moral e religiosa, e muitas vezes ela é tão importante no pensamento, actividades, costumes e religiões que hoje em dia reconhecese o direito humano à água para tais fins ${ }^{42}$.

\footnotetext{
40 TURTON, Anthony; MEISSNER, Richard. The hydrosocial contract and its manifestation in society: a South African case study. In: TURTON, Anthony; HENWOOD, Roland. Hydropolitics in the Developing World: a Southern African Perspective. Pretoria: African Water Issues Research Unit (AWIRU), 2002. p. 37-60. p. 48.

${ }^{41}$ Os números mais recentes apontam para cerca de 700 milhões de pessoas em 43 países assoladas pela escassez de água. Até 2025, 1.8 biliões de pessoas estarão a viver em países ou regiões com escassez de água absoluta, e dois terços da população mundial poderá estar a viver em condições de stress hídrico. E, com o actual cenário de mudanças climáticas, quase metade da população mundial viverá, até 2030, em cenários de stress hídrico elevado, e as estimativas indicam que só em África este número está entre 75 e 250 milhões de habitantes, sendo a região da África sub-sahariana a que maior impacto sofrerá. Vide FOOD AND AGRICULTURE ORGANIZATION OF THE UNITED NATIONS. Coping with water scarcity: an action framework for agriculture and food security. Rome: FAO, 2012. Disponível em: <https://www.un.org/waterforlifedecade/scarcity.shtml>. Acesso em: 18 jun. 2021.

${ }^{42} \mathrm{O}$ GC15, sobre o direito humano à água, prevê que o acesso a fontes tradicionais de água seja protegido contra práticas ilegais e contra a poluição. Esta regra é bastante útil em casos de acesso à água por parte de comunidades
} 
Todas as antigas civilizações da Mesopotâmia tinham cosmogonias baseadas na água e reverenciavam o Tigre e o Eufrates como manifestações da divindade ${ }^{43}$. Na Mitologia grecolatina, Posídon, na Grécia, e Neptuno, em Roma, reinavam sobre os mares e oceanos habitados por numerosas sereias ${ }^{44}$.

Em algumas regiões e ou sociedades o carácter sagrado da água pode até ser incompatível com a titularidade da mesma. De facto, se por um lado todas as sociedades precisam da água para beber, cozinhar, higiene, agricultura e criação de gado, por outro lado algumas sociedades também usam a água para cerimónias religiosas, exercícios, diversão e fins estéticos.

Em religiões como o Hinduísmo, o Islão e o Cristianismo, acredita-se que a água tenha uma função purificadora, de ser um símbolo da vida e da fertilidade, e ainda o poder de combater o mal. De acordo com certa autora, o termo água flui por mais de 200 versos da Bíblia Hebraica, por mais de 100 versos do Novo Testamento Cristão e por mais de 50 versos do Alcorão ${ }^{45}$.

De facto, várias religiões, em momentos e circunstâncias diversos, narram as sagradas escrituras que Moisés, Jesus e Mohamed fazem milagres relacionados com a água. E, da mesma forma que a Bíblia evoca o Dilúvio e menciona diversas tragédias ligadas à água, a mesma Bíblia recomenda os cristãos o uso da água para os batismos.

A relevância das dimensões cultural, religiosa e moral da água notam-se com alguma singularidade no Islão. Nesta religião, a Shari'a devota muita atenção à água. Apesar de presentemente a palavra Shari'a referir-se à palavra árabe cujo significado é Direito Islâmico, em tempos esta mesma palavra já foi entendida como direito da água. ${ }^{46}$ Tal posicionamento é corroborado por Chibli Mallat, para quem shari'a "is the place from which one descends to water... and shari'a in the acceptation of Arabs is the law of water (shur 'at al-ma') concerning the source which is regulated by people who drink, and allow others to drink, from." 47

nativas nas suas terras ancestrais, bem como nos casos de práticas culturais tradicionais, no exemplo das cerimónias religiosas feitas na água, tal como acontece com os ritos de lavagem praticados pelos Hindus no rio Ganges. Vide WORLD HEALTH ORGANIZATION. The Right to Water. Geneva: WHO, 2003, p. 21.

${ }^{43}$ Vide BOUGUERRA, Mohamed Larbi. As Batalhas da água. [s. l.]: Moçambique Editora, 2005. p. 28.

${ }^{44}$ BOUGUERRA, Mohamed Larbi. As Batalhas da água. [s. l.]: Moçambique Editora, 2005. p. 28

${ }^{45}$ Vide JABAILY, Annalisa. Water Rites: a Comparative Study of the Dispossession of American Indians and Palestinians from Natural Resources. Georgetown International Environmental Law Review, v. 16, n. 2, p. 225246, 2004, p. 229.

${ }^{46}$ Vide BOUGUERRA, Mohamed Larbi. As Batalhas da água. [s. 1.]: Moçambique Editora, 2005, p. 36.

${ }^{47}$ Vide CHIBLI MALAT. The Quest for Water Use Principles: Reflections on Shari'a and Custom in the Middle East, in Water in the Middle East: legal Political and Commercial Implications (ALLAN, J.A.; MALLAT, Chibli eds., 1995), apud JABAILY, Annalisa, Water Rites: a Comparative Study of the Dispossession of American 
Estudos feitos por Annalisa Jabaily provam que os juristas que interpretaram a shari'a no passado desenvolveram um sistema altamente sofisticado de regras que refletiram a centralidade da água no Direito Islâmico ${ }^{48}$. Posteriormente, uma codificação mais tardia da Shari'a no Direito Civil Otomano refletiu a importância da regulação da água, uma vez que dedicou 92 artigos aos direitos e à gestão da água ${ }^{49}$.

Segundo a autora que temos vindo a citar, se por um lado há no Direito Islâmico uma diversificação de fontes passíveis de diversas interpretações, essas mesmas fontes podem ser reduzidas a quatro princípios de regulação de água, nos quais o referido direito se reflete, nas mais diversas interpretações que dele pode ser feito: o direito à sede; a necessidade de gestão coletiva da água e uso razoável da mesma; a hierarquia dos usos e o princípio da responsabilidade civil dos poluidores ${ }^{50}$.

E são dados alguns exemplos que justificam tais pronunciamentos. Primeiro, porque tanto a shari'a assim como o Código Civil Otomano articulam um "direito à sede" ou "haq al shafa". E a filosofia presente em ambos é a de que a água, por ser uma dádiva de Deus, pertence a toda a comunidade. De igual modo, nos termos do Código Civil Otomano, a água, tal como o capim e o fogo, são comuns a todos, a ponto de em caso de emergência, o Governo ter o direito de disponibilizar para o público todas as fontes de água, incluindo as pertencentes a particulares. Consequentemente, há um direito primário de shafa (beber) de qualquer indivíduo, para o gado e outros animais domésticos ${ }^{51}$.

Em segundo lugar, as duas fontes que temos vindo a analisar são referidas como regras modelo de uma correta gestão de águas ${ }^{52}$. Aliás, como já referido, ambas preveem uma gestão

\footnotetext{
Indians and Palestinians from Natural Resources. Georgetown International Environmental Law Review, v. 16, p. 225-246, 2004. p. 229

${ }^{48}$ Vide JABAILY, Annalisa. Water Rites: a Comparative Study of the Dispossession of American Indians and Palestinians from Natural Resources. Georgetown International Environmental Law Review, v. 16, n. 2, p. 225246, 2004, p. 229.

${ }^{49}$ Vide Ottoman Civil Law, artigos 1234-1326 (tradução de W.E. Grigsby, 1895), Apud JABAILY, Annalisa. Water Rites: a Comparative Study of the Dispossession of American Indians and Palestinians from Natural Resources. Georgetown International Environmental Law Review, v. 16, n. 2, p. 225-246, 2004, p. 229.

50 Vide JABAILY, Annalisa. Water Rites: a Comparative Study of the Dispossession of American Indians and Palestinians from Natural Resources. Georgetown International Environmental Law Review, v. 16, n. 2, p. $225-$ 246, 2004, p. 230.

${ }^{51}$ Vide MALLAT, Chibli, The Quest for Water Use Principles: Reflections on Shari'a and Custom in the Middle East, in Water in the Middle East: legal Political and Commercial Implications 127, 128 (ALLAN, J.A. \& MALLAT, Chibli, eds., 1995), apud JABAILY, Annalisa. Water Rites: a Comparative Study of the Dispossession of American Indians and Palestinians from Natural Resources. Georgetown International Environmental Law Review, v. 16, n. 2, p. 225-246, 2004, p. 230.

${ }^{52}$ Vide JABAILY, Annalisa, Water Rites: a Comparative Study of the Dispossession of American Indians and Palestinians from Natural Resources. Georgetown International Environmental Law Review, v. 16, p. 225-246, 2004, p. 230
} 
conjunta e um uso razoável das águas. Deste modo, era necessária a devida autorização para o uso privado das águas, e o Estado assumia o controlo da alocação dos recursos de água, a construção de barragens e a organização de sistemas de drenagem. Destarte, os direitos privados eram residuais ${ }^{53}$.

Em terceiro, nota-se claramente uma hierarquia de usos de água na tradição Islâmica e no Código Civil Otomano ${ }^{54}$. No topo, a água para beber tem a mais alta prioridade, a que se seguem os usos domésticos, incluindo o abeberamento dos animais. Qualquer outro fim tal como a agricultura ou a lavagem de roupa são consideradas como sendo das últimas em prioridade $^{55}$.

Finalmente, as mesmas fontes reconhecem o princípio da responsabilidade pelo dano caso o mesmo ocorra às limitadas provisões de água. De acordo com os intérpretes do Qur'an, “o meio ambiente é protegido da degradação humana por injunções específicas contra a perturbação da sua ordem natural através da poluição" "56 , pois o comando de Allah "não pecarás (fassad)"57 tem sido interpretado no sentido de "proibir a disrupção do mundo natural e a poluição dos recursos naturais" ${ }^{\circ 8}$.

Segundo os estudiosos do Direito Islâmico, o uso indevido, a poluição ou degradação das águas é punível ${ }^{59}$, porque a água é considerada como huq uq Allah, ou "direito divino" no

\footnotetext{
${ }^{53}$ Vide MALLAT, Chibli. The Quest for Water Use Principles: Reflections on Shari'a and Custom in the Middle East, in Water in the Middle East: legal Political and Commercial Implications 127, 128 (ALLAN, J.A. \& MALLAT, Chibli eds., 1995), apud JABAILY, Annalisa. Water Rites: a Comparative Study of the Dispossession of American Indians and Palestinians from Natural Resources. Georgetown International Environmental Law Review, v. 16, n. 2, p. 225-246, 2004, p. 230.

${ }^{54}$ Vide CIVIC, Melanne Andromecca. A Comparative Analysis of the Israeli and Arab Water Law Tradition and Insights for Modern Water Sharing Agreements. Denver Journal of International Law and Policy, v. 26, n. 3, p. 437-452,1998, p. 442.

55 Vide CIVIC, Melanne Andromecca. A Comparative Analysis of the Israeli and Arab Water Law Tradition and Insights for Modern Water Sharing Agreements. Denver Journal of International Law and Policy, v. 26, n. 3, p. 437-452,1998, p. 442.

56 Vide FARUQI, Naser I. Islam and Water Management: Overview and Principles. In: Water Management in Islam 1,2 (FARUQI, Naser I.et al. eds., 2001), citado por JABAILY, Annalisa. Water Rites: a Comparative Study of the Dispossession of American Indians and Palestinians from Natural Resources. Georgetown International Environmental Law Review, v. 16, n. 2, p. 225-246, 2004, p. 230.

57 Qur'an 2:11, citado por JABAILY, Annalisa. Water Rites: a Comparative Study of the Dispossession of American Indians and Palestinians from Natural Resources. Georgetown International Environmental Law Review, v. 16, n. 2, p. 225-246, 2004, p. 230.

58 Qur'an 2:11, citado por JABAILY, Annalisa. Water Rites: a Comparative Study of the Dispossession of American Indians and Palestinians from Natural Resources. Georgetown International Environmental Law Review, v. 16, n. 2, p. 225-246, 2004, p. 230.

${ }^{59}$ Vide FARUQI, Naser I., Islam and Water Management: overview and Principles. In: Water Management in Islam 1,2 (FARUQI, Naser I. et al. eds., 2001), citado por JABAILY, Annalisa. Water Rites: a Comparative Study of the Dispossession of American Indians and Palestinians from Natural Resources. Georgetown International Environmental Law Review, v. 16, n. 2, p. 225-246, 2004, p. 230.
} 
sentido de que tais direitos não podem ser remidos, perdoados, relaxados ou comprometidos ${ }^{60}$. Por isso, dar água sempre foi um reconhecimento do laço social e uma marca de não exclusão. É um ato de humanidade, um gesto humano por excelência, recomendado pelo Islão, sendo um dever do Emir e por extensão do Estado, tanto que, por exemplo, na Arábia Saudita, a água é praticamente gratuita, mas o custo da mesma é um segredo de Estado ${ }^{61}$.

Como se pode depreender, a água tem uma importância não só económica e ecológica, mas também cultural e simbólica. A água figura proeminentemente em rituais religiosos tais como o batismo e rituais de banho, e na identidade nacional de muitos povos. Por ser tão fundamental à vida nas mais diversificadas vertentes, sentimentos profundamente enraizados influem, muitas vezes, nas decisões sobre a gestão da água.

\section{CONCLUSÃO}

A água, como bem jurídico, é um bem passível de invocação como direito fundamental. Este facto cria um dever de os Estados garantirem a existência de água para todos e o incumprimento deste dever por parte dos Estados legitima ações com vista à satisfação do direito fundamental à água.

A satisfação do direito à água das populações por parte dos Estados para a satisfação dos diversos fins a que se destina, pode não depender somente da vontade deste, porquanto a garantia da existência de água pode estar condicionada a um fator natural: o facto de a existência de água em quantidades satisfatórias, internamente estar dependente (dependência em relação a cursos de água internacionais, por exemplo).

É necessário que os Estados modernos respeitem os direitos religiosos, sociais e culturais que as populações tem, em relação ao uso que possam fazer dos cursos de água. Para que tal respeito seja reconhecido, não basta declarar a existência formal de tais direitos na legislação dos Estados.

É preciso, acima de tudo, criar condições para que o direito e a religião, o direito e a cultura, sejam analisados do ponto de vista dos componentes ambientais, estudando, inventariando e fazendo respeitar as questões sociais, religiosas e culturais inerentes às práticas das comunidades.

\footnotetext{
${ }^{60}$ Vide AHMAD, Ali. Cosmopolitan Orientation of the Process of International Environmental Law-Making: an Islamic Law Genre 89-90 (2001), citado por JABAILY, Annalisa. Water Rites: a Comparative Study of the Dispossession of American Indians and Palestinians from Natural Resources. Georgetown International Environmental Law Review, v. 16, n. 2, p. 225-246, 2004, p. 230.

${ }^{61}$ Vide BOUGUERRA, Mohamed Larbi. As Batalhas da água. [s. l.]: Moçambique Editora, 2005. p. 39.
} 
Só desta forma poderá ser materializado o desiderato de um reconhecimento amplo e uma fruição completa dos direitos religiosos, sociais e culturais das comunidades, que só podem ser satisfeitos com o pleno reconhecimento da ligação intrínseca que os mesmos tem com a água, e que, sem o devido reconhecimento, perpetuam injustiças não aceitáveis numa sociedade moderna, em pleno século XXI.

\section{REFERÊNCIAS}

BENVENISTI, Eyal. Collective Action in the Utilization of Shared Freshwater: the challenges of International Water Resources Law. The American Journal of International Law, Cambridge University Press, v. 90, n. 3, p. 384-415, 1996.

BOUGUERRA, Mohamed Larbi. As Batalhas da água. [s. 1.]: Moçambique Editora, 2005.

CANELAS DE CASTRO, Paulo. The Future of International Water Law. Lisboa: LusoAmerican Foundation, 2005.

CIVIC, Melanne Andromecca. A Comparative Analysis of the Israeli and Arab Water Law Tradition and Insights for Modern Water Sharing Agreements. Denver Journal of International Law and Policy, v. 26, n. 3, p. 437-452,1998.

DELLAPENNA, Joseph W. A Primer on Groundwater Law. Idaho Law Review, v. 49, n. 2, p. 265-323, 2012.

DELLAPENNA, Joseph W. The Two Rivers and the Land Between: Mesopotamia and the International Law of Transboundary Waters. Brigham Young University (BYU) Law Review, v. 10, n. 2, p. 213-261, 1996.

DU BOIS, François. Water Rights and the Limits of Environmental Law. Journal of Environmental. Law, v. 6, n. 1, p. 73-84, 1994.

FOOD AND AGRICULTURE ORGANIZATION OF THE UNITED NATIONS. Coping with water scarcity: an action framework for agriculture and food security. Rome: FAO, 2012. Disponível em: <https://www.un.org/waterforlifedecade/scarcity.shtml>. Acesso em: 18 jun. 2021.

FOOD AND AGRICULTURE ORGANIZATION OF THE UNITED NATIONS. Water for Sustainable Food and Agriculture: a report produced for the G20 Presidency of Germany. Rome: FAO, 2017. Disponível em: <http://www.fao.org/3/i7959e/i7959e.pdf>.Acesso em: 18 jun. 2021.

GLEICK, Peter H. An introduction to Global Fresh water Issues. In: GLEICK, Peter H. (ed). Water in Crisis: a Guide to the World's Fresh Water Resources. New York: Oxford University Press, 1993. 
GLEICK, Peter et al. The Risks and Benefits of Globalization and Privatization of Fresh Water. Oakland: Pacific Institute For Studies in Development, Environment and Security, 2002.

HASSAN, Fekri A. Water for Peace: a Cultural Strategy. In: UNESCO. History and Future of Shared Water Resources. [s. l.]: UNESCO-IHP, 2003. (PC/CP series, n. 6). [p. 4-26].

HASSAN, Fekri A. Water Management and Early Civilizations: from Cooperation to Conflict. In: UNESCO. History and Future of Shared Water Resources. [s. l.]: UNESCO-IHP, 2003. (PC/CP series, n. 6). [p. 110-127].

HODGSON, Stephen. Modern water rights: theory and practice. Rome: FAO, 2006. (FAO Legislative Study, n. 92).

JABAILY, Annalisa. Water Rites: a Comparative Study of the Dispossession of American Indians and Palestinians from Natural Resources. Georgetown International Environmental Law Review, v. 16, n. 2, p. 225-246, 2004.

LUTERBACHER, Urs; WIEGANDT, Ellen. Cooperation or Confrontation: Sustainable Water Use in an International Context. In: WEISS, Edith Brown; CHAZOURNES, Laurence Boisson de; BERNASCONI-OSTERWALDER Nathalie. Fresh Water and International Economic Law. Oxford; New York: Oxford University Press, 2005. [s. p.].

MARAVILLA, Christopher Scott. The Canadian Bulk Water Moratorium and Its Implications for NAFTA. Currents: International Trade Law Journal, v. 10, n. 1, p. 29-36, 2001.

MCCAFFREY, Stephen C. Water, Water Everywhere, but too Few Drops to Drink: the Coming Fresh Water Crisis and International Environmental Law. Denver Journal of International Law \& Policy, v. 28, n. 3, p. 325-338, 2000.

NARDONE, Rona. Like Oil and Water: the WTO and the World's Water Resources. Connecticut Journal of International Law, v. 19, n. 1, p. 183-208, 2003.

NICHOLSON, Simon. Water Scarcity. Conflict and International Water Law: an Examination of the Regime Established by the UN Convention on International Watercourses. New Zealand Journal of Environmental Law, v. 5, p. 91-126, 2001.

PERCIVAL, Val.; HOMER-DIXON, Thomas. Environmental Scarcity and Violent Conflict: the case of South Africa, Journal of Peace research, v. 35, n. 3, p. 279-298, 1998.

SERRA, Carlos Manuel; CUNHA, Fernando. Manual de Direito do Ambiente. 2 ed. Maputo: Centro de Formação Jurídica e Judiciária, 2008.

TARLOCK A. Dan; MCMURRAY, James C. The Law of Later Developing Riparian States: the case of Afghanistan. New York University Environmental Law Journal., v. 12, n. 3, p. 711$763,2004$.

TARLOCK, A. Dan. Five Views of the Great Lakes and Why They Might Matter. Minnesota Journal of International Law, v. 15, n. 1, p. 21-41, 2006. 
TARLOCK, A. Dan. How well can International Water Allocation Regimes Adapt to Global Climate Change? Denver Journal of International Law \& Policy, v. 9, p. 423-450, 2000.

TURTON, Anthony; MEISSNER, Richard. The hydrosocial contract and its manifestation in society: a South African case study. In: TURTON, Anthony; HENWOOD, Roland. Hydropolitics in the Developing World: a Southern African Perspective. Pretoria: African Water Issues Research Unit (AWIRU), 2002. p. 37-60.

UNITED NATIONS. General Assembly. Official Records of the General Assembly, FortyNinth Session, Supplement n. 10 (A/49/10). Commentary to Article 10 of the UN Watercourses Convention, ILC Report on the work of its Forty-Sixth Session. 1994.

WEISS, Edith Brown. The Evolution of International Water Law. Leiden/Boston: Martinus Nijhoff Publishers, 2009.

WORLD BANK. World Development Indicators. 2005. Disponível em <httpllwww.worldbank.org/data/wdi/environment.html>. Acesso em: 13 Fev. 2017.

WORLD HEALTH ORGANIZATION. The Right to Water. Geneva: WHO, 2003.

WORLD WATER FORUM. Ministerial Declaration of the Hague on Water Security in the $21^{\text {st }}$ Centuary. Second World Water Forum, 2000. Disponível em: <http://www.worldwaterforum.net/index2.html>. Acesso em 12 Mar. 2013.

WOUTERS, Patricia; HU, Desheng; ZHANG, Jiebin; TARLOCK A. Dan; ANDREWSSPEED, Philip. The New Development of Water Law in China. University of Denver Water Law Review, v. 7, n. 2, 243-308, 2004.

WOUTERS, Patricia; SALMAN, Salman M. A.; JONES, Patricia. The Legal Response to the World's Water Crisis: What Legacy from the Hague - What Future in Kyoto. University of Denver Water Law Review, v. 4, n. 2, p. 418-425, 2001.

\section{DADOS DA PUBLICAÇÃO}

Categoria: artigo submetido ao double-blind review.

Recebido em: 30/09/2020.

Aceito em: 10/07/2021 